\title{
CAN DISLOCATIONS ACCELERATE THROUGH THE SHEAR-WAVE SPEED "BARRIER"?
}

\author{
Xanthippi Markenscoff, Surong Huang \\ University of California, San Diego \\ 9500 Gilman Drive, La Jolla, CA 92093
}

\begin{abstract}
The question of whether a dislocation can accelerate through the shear-wave speed "barrier" is addressed by analyzing the transient motion of a Volterra dislocation at the instant when the velocity equals the shear-wave speed in the presence of acceleration, which requires an asymptotic analysis at a double root (-at the transition from subsonic to supersonic a pair of complex conjugate roots becomes a double real - ). The stresses carried by the forming Mach wave fronts depend on the acceleration at this instant and are found to be $O\left(\ln \mathrm{r} / \mathrm{r}^{1 / 2}\right)$ singular for a Volterra dislocation both screw and edge. The energy required to push the dislocation through the shear-wave speed "barrier" is determined by means of the "contour-independent" dynamic $J$ integral which defines the self-force on a moving defect, and is obtained as a function of the acceleration as it crosses the "barrier". While for a Volterra dislocation the energy-rate is singular at this instant, for a more physically realistic ramp-core "smeared" dislocation model, approximating the Volterra dislocation by a delta sequence, this energy rate is obtained by convolution and is finite, with the same result obtained by the theory of distributions. Thus, crossing the "barrier" is theoretically possible as recent experimental evidence in the literature suggests. A "cut-off" constant that remains undetermined will be found in a multiscale analysis by the matching of the self-force based on atomistic calculations modeling the core to the continuum far-field one obtained here. For decelerating motion through the shear-wave speed "barrier" this energy is released as dissipation.
\end{abstract}

\section{INTRODUCTION}

The question of whether dislocations under shock loading in metals at low temperatures and in tectonic faults can cross the shear-wave speed barrier $c_{2}$ has been open for over fifty years, and it was considered until recently prohibitive. However, new results show convincingly that indeed transient supersonic motion is possible and dislocations do accelerate through the shear-wave speed "barrier" both in metals and in geophysics. Then, the questions arise of determining the energy rate required to accelerate the dislocation through the shear-wave speed "barrier" and of the stress carried by the Mach supershear fronts, the shape of which also depends on the acceleration of the dislocation. Gumbsch and Gao [1] showed by molecular simulation that in tungsten dislocation motion faster than the speed of sound is possible if generated as such, while in $\mathrm{Al}, \mathrm{Ni}$ and $\mathrm{Al} / \mathrm{Mg}$ alloys, Olmsted et.al. [2] shown by numerical simulation that dislocations do accelerate through the shear-wave speed "barrier" after which they become unstable and dissociate into partials. Further evidence for transient supersonic dislocation motion in metals is presented in 
$[3,4,5]$, while evidence of supershear dislocation motion in earthquakes has been reported and is now considered established $[6,7,8,9]$. The physical observations reported above show that the physical phenomena are transient in nature, which necessitates accelerating dislocation motion analysis of the radiated fields and the corresponding energetics. We present here the results of the transient analysis as the dislocation is accelerating/decelerating through the shear-wave speed "barrier" for the stress carried by the forming Mach front, and the corresponding energy-rate required to generate it. While for a Volterra dislocation the stresses are $\mathrm{O}\left(\operatorname{lnr} / \mathrm{r}^{1 / 2}\right)$ singular, for a smeared out core they are regularized and singular. To the leading order the result agrees with the one obtained by the theory of distributions, and it provides the far field to match atomistic calculations of the core in a multiscale analysis.

\section{FORMATION OF THE MACH ENVELOPE AT THE INSTANT OF THE DISLOCATION CROSSING THE SHEAR-WAVE SPEED "BARRIER"}

The classical works of Weertman $[10,11,12]$ present the analysis of the stress field and the energetics of the steady state supersonic motion. While crossing of the barrier has been assumed prohibitive due to the $\left(c_{2}^{2}-i^{2}(t)\right)^{-\frac{1}{2}}$ "relativistic" singularity which appears in the steady-state analysis, the present analysis aims at addressing the energetics of crossing the barrier by means of the transient analysis of a screw/edge dislocation in a general motion $x=l(t)$, evaluated at the instant when the velocity $i(t)$ equals the shearwave speed in the presence of acceleration $\ddot{l}(t)$, and the evaluation of the self-force at this instant both for a Volterra and ramp-core model. In the transient analysis to the secondorder terms (that account for the acceleration), the term $\left(c_{2}^{2}-i^{2}\right)$ is not zero any longer, but depends on the acceleration $\ddot{l}(t)$ at this instant. At this transition to supersonic, a pair of complex conjugate roots becomes a double real splitting subsequently into two real ones. The asymptotic analysis is performed at this double root.

The analysis performed evaluates the stress on the forming Mach cone, which is the envelope of the wavelets emitted by the dislocation during the motion (Figure 1). General accelerating motion of dislocations has been analyzed by Eshelby [13,14,15,16,17], also [18] (for complete early references, see [12]). However, crossing the shear wave speed barrier has not been analyzed as to the present time.

For a Volterra dislocation of Burgers vector $\Delta$ umoving along the $x$ axis according to $x=l(t)$, in a wave-front asymptotic analysis of the transient (rather than steady-state) radiated fields at the Mach cone, the stress on the Mach cone $\left(x, z, t^{*}\right)$ is found to be a delta function, following an analysis as in [19, 20]:

(a) for screw dislocation:

$$
\sigma_{x z}=\mu \frac{\partial u}{\partial z}=\mu \frac{\Delta u}{2} \cdot \frac{z^{2}\left(t^{*}-\tau^{*}\right)^{2} \cdot i\left(\tau^{*}\right)}{\left[\left(x-l\left(\tau^{*}\right)\right)^{2}+z^{2}\right]^{2} \cdot\left(b^{2}-\frac{1}{i\left(\tau^{*}\right)^{2}}\right)^{\frac{1}{2}}} \cdot \delta\left(t-t^{*}\right),
$$




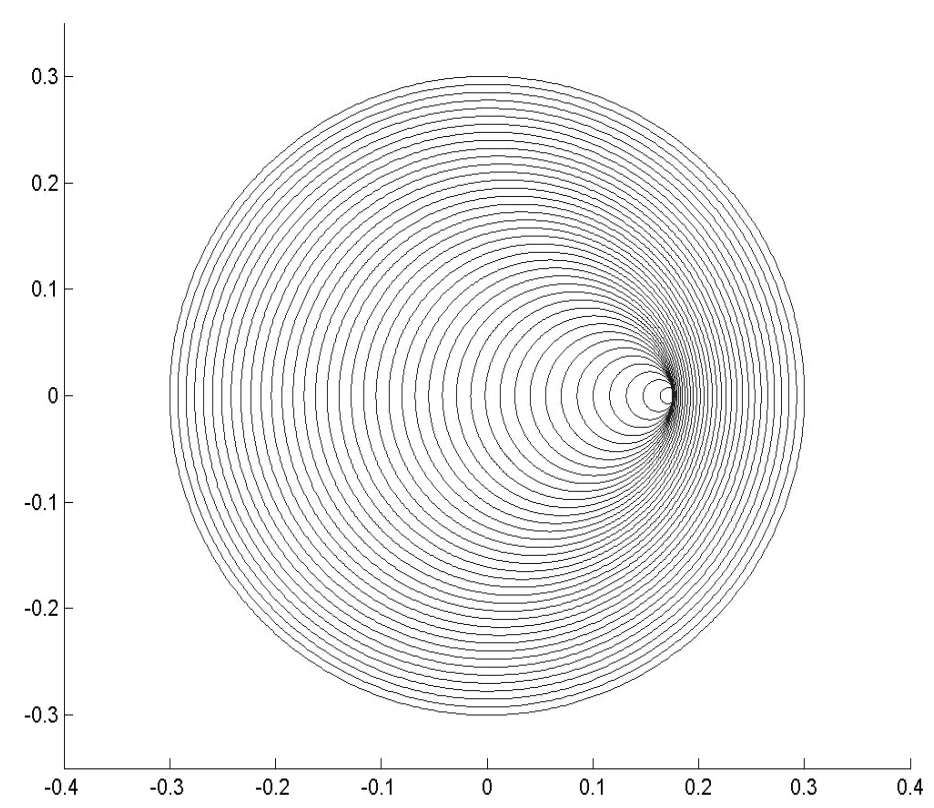

Fig. 1. Forming Mach cone for a dislocation accelerating through the shear wave speed barrier. At $t=0.3$ for dislocation motion $l(t)=2 t^{2}$, the motion becomes supersonic at $t=0.25$; the quantities are dimensionless and the speed $c_{2}$ is normalized to 1 for all figures

(b) for edge dislocation [21]:

$$
\sigma_{x z}=\mu \frac{-(\Delta u)}{2 b^{2}} \frac{\left(z^{2}-\left(x-l\left(\tau^{*}\right)\right)^{2}\right)^{2}\left(t^{*}-\tau^{*}\right)^{4} \cdot i\left(\tau^{*}\right)}{\left[\left(x-l\left(\tau^{*}\right)\right)^{2}+z^{2}\right]^{4}\left(b^{2}-\frac{1}{i\left(\tau^{*}\right)^{2}}\right)^{\frac{1}{2}}} \delta\left(t-t^{*}\right),
$$

where $b$ denotes the shear-wave slowness, $b=1 / c_{2}>1 / i(t)$ for supersonic motion; $\tau^{*}$ is the time of emission of a wavelet contributing to the Mach cone. The Mach cone is the envelope of these wavelets, and satisfyies the following two equations:

$$
\begin{aligned}
& f\left(\tau^{*}\right)=t^{*}-\tau^{*}-b \sqrt{\left(x-l\left(\tau^{*}\right)\right)^{2}+z^{2}}=0, \\
& \left.\frac{d}{d \tau}\left(t^{*}-\tau-b \sqrt{(x-l(\tau))^{2}+z^{2}}\right)\right|_{\tau=\tau^{*}}=0
\end{aligned}
$$

This envelope starts forming at the instant when $i(t)=c_{2}$; for subsonic motion the roots of equation (3a) are complex conjugate, which coalesce into a double real $\tau^{*}$ at the instant of the dislocation motion becoming supersonic, and split into two real ones $\left(\tau_{0}, \tau_{1}\right)$ after it crosses $c_{2}$ (Figure $2 \mathrm{~b}$ ). The function $f(\tau)=t-\tau-b \sqrt{(x-l(\tau))^{2}+z^{2}}=0$ with $t$ 


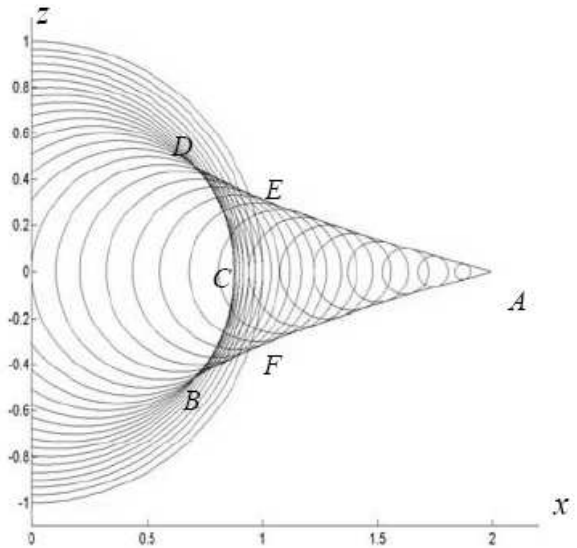

Fig. 2a. Mach wave front at $t=1$ for the motion $l(t)=2 t^{2}$; the motion is supersonic and the envelope grows out of the circle with radius $r=1$

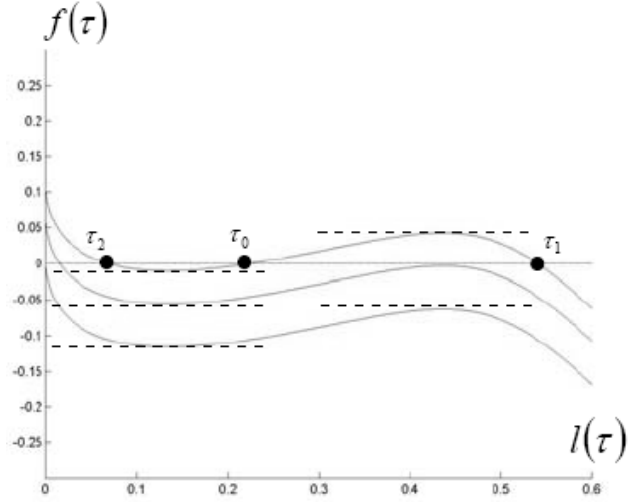

Fig. 2b. $f(\tau)=t-\tau-b \sqrt{(x-l(\tau))^{2}+z^{2}}$, $l(\tau)=q \tau^{2} / 2$; with $q=4, b=1, x=0.5$, $z=0.1$

as a parameter $t$ exhibits imaginary or real roots; the real roots relate to the wave fronts $\mathrm{AB}$ (maximum of $f(\tau)$ ), and BC (minimum of $f(\tau)$ ) in Figure 2a. The minimum of $f(\tau)$ gives no delta function contribution to the stress at the front, as shown in [19], so that the stress field is continuous as we approach the front BCD (Figure 2a). The limit $\tau_{0}, \tau_{1} \rightarrow \tau^{*}$ is taken as the maximum of $f(\tau)$ is approached, and the two real roots coincide to a double real one $\xi^{*}$. This again corresponds to the Mach front AB (Figure 2a) crossing the field point near the current position of the dislocation, i.e. $x \rightarrow l\left(\tau^{*}\right)$.

While expressions (1) and (2) give the stress on the Mach cone for $i(t)>c_{2}$, an analysis at the instant when $i(t)=c_{2}$ is required. At this point, i.e. $\dot{l}(t)=c_{2}$, a wave-front asymptotic analysis to the second order $[20] l(t)=l(\tau)+(t-\tau) \dot{l}(\tau)+\frac{1}{2}(t-\tau)^{2} \ddot{l}(\tau)+$ $o(t-\tau)^{2}$ is performed and the coefficients of the delta function of the stress on the forming Mach cone in expressions (1) and (2) are now depending on the acceleration $\ddot{l}(t)$ :

(a) for screw dislocation [20]:

$$
\begin{aligned}
\sigma_{x z}=\mu \frac{\partial u}{\partial z}=\mu \lim _{t \rightarrow t^{*}} \lim _{\tau_{0}, \tau_{1} \rightarrow \tau^{*}} \frac{\Delta u}{2 \pi} \frac{m^{2} b \dot{l}\left(\tau^{*}\right)}{\left(1+m^{2}\right)\left|\ddot{l}\left(\tau^{*}\right)\left(x-l\left(\tau^{*}\right)\right)\right|^{\frac{1}{2}}} \\
\times\left.\ln \left|\left(\tau-\tau^{*}\right)\right|\right|_{\tau_{0}} ^{\tau_{1}} \cdot \delta\left(t-t^{*}\right) \equiv \bar{A} \cdot \delta\left(t-t^{*}\right)
\end{aligned}
$$

(b) for edge dislocation [21]:

$$
\begin{aligned}
\sigma_{x z}=\mu \lim _{t \rightarrow t^{*}} \lim _{\tau_{0}, \tau_{1} \rightarrow \tau^{*}} \frac{-(\Delta u)}{2 \pi} \frac{\left(m^{2}-1\right)^{2} b \dot{l}\left(\tau^{*}\right)}{\left(1+m^{2}\right)^{2}\left|\ddot{l}\left(\tau^{*}\right)\left(x-l\left(\tau^{*}\right)\right)\right|^{\frac{1}{2}}} \\
\quad \times \ln \left|\left(\tau-\tau^{*}\right)\right|_{\tau_{0}}^{\tau_{1}} \cdot \delta\left(t-t^{*}\right)=\bar{B} \cdot \delta\left(t-t^{*}\right),
\end{aligned}
$$


where, again, $\left(\tau_{0}, \tau_{1}\right)$ is the interval of emission of wavelets that contribute to the forming Mach cone (Figure $2 \mathrm{~b}$ ), at an angle $m \equiv z /\left(x-l\left(\tau^{*}\right)\right)$. The singularity in the coefficient of the delta function for the stress on the forming Mach cone in expressions (4) and (5) is eliminated by applying a more physically realistic ramp-core model $[12,20]$. While for a Volterra dislocation the volume integral is singular, for a ramp-core model where the displacement is modeled by $\operatorname{an} \arctan (x / \varepsilon)$ function rather than a step function $H(x)$ on the slip-plane $z=0$; i.e.

$H_{\varepsilon}(x)=H(x) * \frac{1}{\pi} \frac{\varepsilon}{\varepsilon^{2}+x^{2}}==\left(\frac{1}{\pi}\right) \arctan \left(\frac{x}{\varepsilon}\right)+\frac{1}{2}$, the singularity is smoothed out by convolution. The constant epsilon remains undetermined and will be found by matching this continuum far field to the one from atomistic calculations at the core. Thus, the stress at the forming Mach cone, as it accelerates through the shear-wave speed barrier, is finite [20], although near about $1 / 30$ the theoretical strength of the material, as estimated in [23]. The conclusion is that the ramp-core dislocation can accelerate through the shear-wave speed barrier.

\section{SELF - FORCE AND THE ENERGETICS OF A DISLOCATION AS IT ACCELERATES / DECELERATES THROUGH THE SHEAR - WAVE SPEED "BARRIER"}

The required driving force, or self-force, needed to effectuate such motion is obtained by dynamic $J$ integral (e.g. [17]), based on Noether's theorem expressing the requirement of invariance of the Lagrangian W-T functional under an infinitestimal translation of the defect. The self-force is given by the contour independent expression

$$
F_{l}=\int_{V} \frac{\partial}{\partial t}\left[\rho \dot{u}_{i} u_{i, l}\right] d V+\int_{S}\left[(W-T) \delta_{l j}-u_{i, l} \sigma_{i j}\right] d S_{j}
$$

where $V$ is a volume integral and $\mathrm{S}$ a surface integral surrounding the moving dislocation. This expression for the self-force for moving cracks coincides with the energy-release rate [24], [25], while for a general defect is interpreted (Markensoff, 2006) as the difference of the work of the tractions in the celebrated Eshelby thought experiment to produce a translation of the defect by $\delta l$, when comparing two motions differing by $\delta l$ for all times. The self-force is related to the energy-release rate $\dot{E}$ by $F=\dot{\mathrm{E}} / \dot{l}(t)$. For subsonic motion it has been computed by regularizing the integrals in the in the sense of distributions and by smearing the core, both agreeing to the leading (logarithmic) order.

Here, expression (6) is evaluated at the instant of the acceleration through the shear-wave speed barrier, and the self-force $F$ at the instant of crossing the shear-wave speed barrier for a screw dislocation is a delta function in time :

$$
\begin{aligned}
F_{l}(t)=\lim _{z \rightarrow 0, x \rightarrow l(t *)} \mu & \frac{b}{2 \pi} \frac{1}{\left|\ddot{l}\left(t^{*}\right)\right|^{\frac{1}{2}}} \int_{-\infty}^{\infty} \frac{z^{2}}{\left(\left(x-l\left(t^{*}\right)-\xi\right)^{2}+z^{2}\right)^{\frac{5}{4}}} \\
& \times \ln \left(x-l\left(t^{*}\right)-\xi\right) \frac{\varepsilon}{\varepsilon^{2}+\xi^{2}} d \xi \cdot \delta\left(t-t^{*}\right)
\end{aligned}
$$




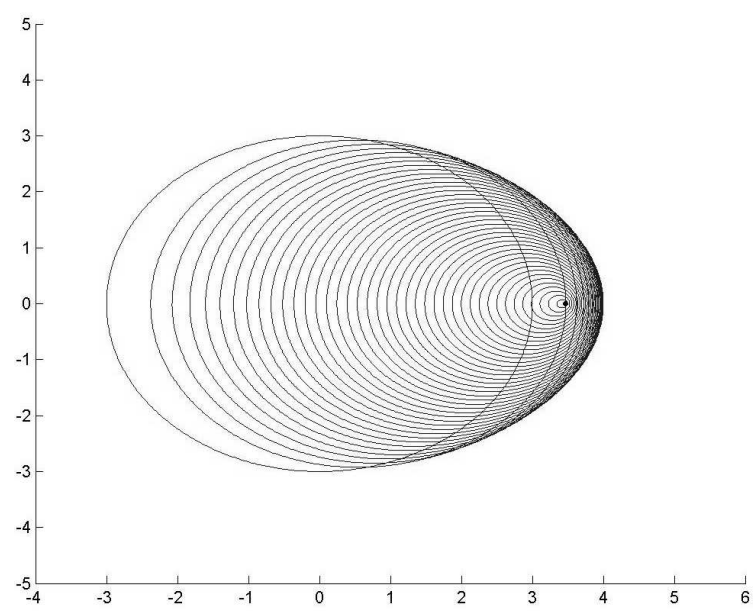

Fig. 3. Detachment of the Mach cone from the decelerating dislocation The dark point refers to the current position of the dislocation moving with $x=2 t^{\frac{1}{2}}$ at time $t=3$

where $\bar{A}$ is defined in equation (4) for screw dislocation. The self-force given by equation (7) is equal to the energy-release-rate $\dot{E}$ required to be externally supplied in order to move the dislocation by $\delta l$ as it accelerates with $\ddot{l}(t)$ at the instant when the dislocation velocity $i(t)=c_{2}$. The constant epsilon will have to be determined by matching the far fields/self-forces in a multiscale analysis where the core is modeled atomistically.

The analysis is also performed in case of a motion decelerating through the shearwave speed into the subsonic regime. Now, the dislocation detaches from the Mach front (Figure 3 ), with a positive self-force associated with the release of an energy rate $\dot{\mathrm{E}}=F \cdot \dot{l}$ (of the same magnitude as in the accelerating case above, but with a negative value of the acceleration $\ddot{l}(t))$ which is now dissipated into the material, rather than required to be externally supplied [27].

\section{ACKNOWLEDGEMENTS}

The support of the National Science Foundation grant CMS-0555280 is gratefully acknowledged.

\section{REFERENCES}

[1] P. Gumbsch, H. Gao, Dislocations Faster than the Speed of Sound, Science 283 (1999) 5404.

[2] D. L. Olmsted, L.G. Hector, W. A. Curtin, R. J. Clifton, Atomistic simulations of dislocation mobility in $\mathrm{Al}, \mathrm{Ni}$ and $\mathrm{Al} / \mathrm{Mg}$, Modeling And Simulation in Engineering 13 (2005), 3.

[3] J. Marian, A. Caro, Moving dislocations in disordered alloys: Connecting continuum and discrete models with atomistic simulations, Physical Review 74 (2) (2006).

[4] J. A. Y. Vandersall, B. D. Wirth, Supersonic dislocation stability and nano-twin formation at high strain rate, Philosophical Magazine 84 (35) (2004).

[5] D. Mordehai, I. Kelson, G. Makov, Nonplanar core and dynamical behavior of screw dislocations in copper at high velocities, Physical Review $\mathbf{7 4}$ (18) (2006). 
[6] E. M. Dunham, R. J. Archuleta, Evidence for a Supershear Transient during the 2002 Denali Fault Earthquake, E. M.Bull. Seismol. Soc. Am. 94, S256 (2004).

[7] M. Bouchon, M.Valle'e, Observation of Long Supershear Rupture During the Magnitude 8.1 Kunlunshan Earthquake, Science 301 (2003) 824.

[8] M. Bouchon and Hayrullah Karabulut, The Aftershock Signature of Supershear Earthquakes, Science 320 (2008) 1323-1325.

[9] Shamita Das, The Need to Study Speed, Science 317 (2007) 905-906.

[10] Weertman J., Uniformly moving transonic and supersonic dislocations, Journal of Applied Physics. 38 (1967) (3) 5293-5301.

[11] Weertman J., Mathematical Theory of Dislocations, T. Mura, Ed. (American Society of Mechanical Engineers, New York, 1969), pp. 178-202.

[12] Weertman J. and Weertman J. R., Moving dislocations, Dislocations in Solids 3 (1980) 1-59, North Holland.

[13] Eshelby J.D., Uniformly moving dislocations, Proc. Phys. Soc. A62 (1949) 307-314.

[14] Eshelby J. D., The equation of motion of a dislocation. Phys. Rev. 90 (1953) 248-255.

[15] Eshelby J. D., Supersonic dislocations and dislocations in dispersive media, Proc. Phys. Soc. B69 (1956) 1013-1019.

[16] Eshelby J. D., The interaction of kinks and elastic waves, Proc. Roy. Soc. A266 (1962) 222246.

[17] Eshelby J. D., Energy relation of the energy-momentum tensor in continuum mechanics. In book Inelastic Behavior of Solids, ed. By M.F. Kannien, W.F. Adler, A.R. Rosenfeld, and R.I. Taffee (1970).

See also: Markenscoff, X. and Gupta, A., editors, J.D.Eshelby's Collected Works: The Mechanics of Defects and Inhomogeneities, Springer (2006).

[18] Markenscoff X. and Clifton R. J., The nonuniformly moving edge dislocation, J.Mech. Phys. Solids 29 (1981) (3) 253-262

[19] Callias C.and Markenscoff X., The nonuniform motion of a supersonic dislocation, Quarterly of Applied Mathematics, 1980.

[20] Markenscoff X. and Huang S., Analysis for a screw dislocation accelerating through the shearwave speed barrier, Journal of the Mechanics and Physics of Solids 56 (2008) 2225-2239

[21] Huang S. and Markenscoff X., Is transonic dislocation motion possible? Singularity analysis for an edge dislocation accelerating through the shear wave speed barrier (transonic motion), Experimental Mechanics, special issue in honor of R.J. Clifton (2008). (online)

[22] Markenscoff X. and Ni L., The transient motion of a dislocation with a ramp like core, Journal of the Mechanics and Physics of Solids 49 (2001) 1603-1619.

[23] Clifton R. J. and Markenscoff X., Radiation from non-uniformly moving dislocation and elastic precursor decay, J. Mech. Phys. Solids 29 (1981) (3) 227-251.

[24] Ni L. and Markenscoff X., The self-force and effective mass of an accelerating dislocation: I. screw dislocation, Journal of the Mechanics and Physics of Solids 56 (2008) 1348-1379.

[25] L. B. Freund, J.Elasticity 2 (1972) 341-349.

[26] G. A. Maugin, Material Inhomogeneities in Elasticity, Chapman and Hall, London (1993).

[27] Markenscoff, X and Huang, S. ,The Energetics of Dislocations Accelerating/Decelerating through the shear-wave speed barrier, Appl.Phys.Lett. 94 ,2, DOI: 10.1063/1.3072351, (2009). 


\section{CÁC LỆCH MẠNG CÓ THỂ TĂNG TỐC VƯợT QUA GIỚI HẠN VẬN TỐC CỦA SÓNG TRƯợT?}

Vấn dề liệu các lệch mạng có thể tăng tốc vượt qua giới hạn vận tốc của sóng trượt hay không được đề cập bằng cách phân tích chuyển động chuyển tiếp của lệch mạng Volterra ở thời điểm khi tốc độ bằng tốc độ sóng trượt và có gia tốc, mà đòi hỏi phân tích tiệm cận ở nghiệm kép (từ tốc độ dưới ngưỡng tới siêu âm cặp nghiệm phức liên hợp trở thành nghiệm thực kép). ứng xuất gây ra bởi sóng Mach phụ thuộc gia tốc ở thời điểm đó và có độ kỳ dị $0\left(\ln r / r^{1 / 2}\right)$ cho lệch mạng Volterra cả xoắn và cạnh. Năng lượng cần thiết để đẩy lệch mạng qua giới hạn vận tốc sóng trượt được xác định bởi tích phân động lực $J$ (không phụ thuộc đường lấy tích phân) xác định lực tự thân lên khuyết tật chuyển động, và được nhận như là hàm gia tốc khi nó vượt qua giới hạn. Trong khi đối với lệch mạng Volterra độ tăng năng lượng là kỳ dị ở thời điểm này, cho một mô hình lệch mạng hiện thực hơn, xấp xỉ lệch mạng Volterra bởi chuỗi delta, độ tăng năng lượng này được nhận là hữu hạn với kết quả tương tự như lý thuyết phân bố. Như thế vượt qua ngưỡng về lý thuyết là có thể cũng như bằng chứng thực nghiệm từ các tài liệu đã chỉ ra. Hằng số cắt chưa biết sẽ được tìm qua phân tích đa cấp tương thích lực tự thân trên cơ sở mô hình nguyên tử cho vùng tâm với mô hình liên tục cho vùng xa tâm nhận được ở đây. Với chuyển động chậm dần qua ngưỡng vận tốc sóng trượt năng lượng này được giải phóng đưới dạng hao tán. 